\title{
The Incentive Model in Supply Chain with Trade Credit and Default Risk
}

\author{
Hong Cheng $\mathbb{D}$, , ${ }^{1}$ Yingsheng Su $\mathbb{D},{ }^{2}$ Jinjiang Yan, ${ }^{3}$ Xianyu Wang, ${ }^{3}$ and Mingyang Li $\mathbb{D}^{1}$ \\ ${ }^{1}$ College of Management Science, Chengdu University of Technology, Chengdu, China \\ ${ }^{2}$ School of Statistics, Southwestern University of Finance and Economics, Chengdu, China \\ ${ }^{3}$ Business School, Sichuan University, Chengdu, China \\ Correspondence should be addressed to Yingsheng Su; suys@swufe.edu.cn
}

Received 29 January 2019; Revised 3 April 2019; Accepted 11 April 2019; Published 2 May 2019

Guest Editor: Rosario Domingo

Copyright (c) 2019 Hong Cheng et al. This is an open access article distributed under the Creative Commons Attribution License, which permits unrestricted use, distribution, and reproduction in any medium, provided the original work is properly cited.

Trade credit is widely used for its advantages. However, trade credit also brings default risk to the manufacturer due to the uncertain demand. And moral hazard may aggravate the default risk. The purpose of this paper is to investigate the role of moral hazard in trade credit and explore incentive contract under uncertain demand and asymmetric information. We consider a two-echelon supply chain consisting of a risk-neutral retailer ordering a single product from a risk-neutral manufacturer. Market demand is stochastic and is influenced by retailer's sales effort which is his private information. Incentive theory is used to develop the principal-agent model and get the incentive contract from the manufacturer's perspective. Results show that the retailer will reduce his effort level to get more profit and the manufacturer's profit will be reduced, in the case of asymmetric information. Facing this result, the manufacturer will reduce the order quantity in incentive contract to lessen his losses. Numerical examples are provided to illustrate all these theoretical results and to draw managerial insights.

\section{Introduction}

Emerging trends and practices have joint considered capital flow, material flow, and information flow in supply chain [1]. The typical financial resources for firms in supply chain include trade credit, bank credit, and capital budget. This paper focuses on the trade credit. Trade credit is widely used, with a survey indicating that companies were granting trade credits for up to $80 \%$ of their business transactions in some European countries [2].

Trade credit cannot be replaced by bank loans for its advantages. Comparatively speaking, trade credit is more accessible and less expensive than bank loans when a buyer faces constrained finance. And trade credit has been proven to be one of the more effective competitive tools for product market lenders [3, 4]. It was found in a study on Spanish firms that SMEs with credit constrained depended on trade credit instead of bank loans, particularly during the financial crisis [5]. It was also concluded that trade credit had advantages for both the supplier and the retailer in the supply chain [6].
Trade credit is widespread and has been shown to be good for the supply chain. But it can also result in default risks and even bankrupt risks to the manufacturer if the retailer is unable to settle the account on time. For example, when demand decreases suddenly at a certain time because of the uncertain market demand, the retailer may not have sufficient funds to pay the manufacturer because of bad sales. Therefore, the unsold losses are transferred from the retailer to the manufacturer because of the trade credit, which results in a loss to the manufacturer, and even results in a domino effect and a supply chain crisis. For example, the 2008 US subprime crisis resulted in an economic downturn in many countries, and some small open economies that had little direct exposure to the US subprime mortgage market suffered from a fall in export demand by up to $30 \%$ in the second half of 2008 [7]. This means that providing trade credit could be risky for the manufacturer when facing uncertain demand.

Such risks may be worse when the retailer has private information about his sales effort level which can influence the uncertain demand. Cachon (2003) summarized that the moral hazard caused by retailer's private information of sales 
effort level would reduce the manufacturer's profit and the efficiency of the supply chain [8]. Because the effort level is the retailer's private information and the retailer will pay effort to maximize his profit instead of paying as the request. The quantity discount contract can fix that when there is no trade credit. Uncertain demand and asymmetric information are common in commercial activities. Therefore, including the moral hazard and the uncertain demand, which can result in default risk, is critical when analyzing trade credit in supply chain management. When studying trade credit with default risk few papers study moral hazard. Therefore, this paper seeks to fill this gap by studying the moral hazard and default risk in trade credit.

In this paper, our motivation for developing principalagent models under the situation of symmetric information and the situation of asymmetric information separately is to investigate the impact of moral hazard on trade credit and explore the incentive contract. What is the effect of trade credit with uncertain demand influenced by retailer's sales effort? How does the moral hazard influence the trade credit? What contract can weaken the moral hazard? Our research will attempt to answer these questions.

The remainder of the paper is structured as follows. Section 2 provides a review of existing article about trade credit in supply chain. Section 3 presents assumptions and notations and describes the basic model. The model under symmetric information is developed and analyzed in Section 4. The influence of moral hazard under asymmetric information is analyzed and incentive contract is derived in Section 5, followed by an application example in Section 6 . Finally, Section 7 draws conclusions.

\section{Literature Review}

Since Goyal (1985) first introduced the economic order quantity (EOQ) model to study trade credit in supply chains [9], the model has been extended to deteriorating items and two or three level trade credits from the retailer's view to determine specific replenishment policies. For example, Aggarwal and Jaggi (1995) built the model for deteriorating items under trade credit [10], and Teng (2009) extended the model to two-level trade credit [11], in which the supplier offers trade credit to the retailers and the retailer offers trade credit to their customers. Then, Tiwari (2018) considered this study under two-level partial trade credits in supply chain [12]. Besides deteriorating items, Lin et al. (2019) considered the variable capacity utilization under trade credit [13]. Feng and Chan (2019) concerned manufacturer's production cost which follows a learning curve effect and studied the optimal lot-sizing and pricing strategies with both upstream and downstream trade credit [14]. Chung et al. (2014) [15] also developed an economic production quantity inventory model for deteriorating items under a two-level trade credit to determine an optimal replenishment policy. Along with deteriorating items and two-level trade credit, Liao et al. (2017) also considered partial trade credit and two storage facilities in situations when the supplier's own warehouse was not sufficient for the order quantity and a rented warehouse was required for the excess units [16]. Some more literatures focused on the trade credit influence on decision-making in supply chain. For example, Zhong et al. (2018) introduced the trade credit to supply chain network design [1], and HosseiniMotlagh et al. (2018) introduced trade credit to the collaborative model for coordination in a supply chain consisting of one monopolistic manufacturer and two competing retailers [17].

The literatures above have assumed that market demand is constant or depending on the retail price. And under this assumption, some literatures have sought to coordinate the supply chain inventories under a trade credit environment to enhance supply chain efficiency. Luo (2007), for example, analyzed supply chain coordination using credit periods [18], and Yang et al. (2014) examined the efficiency of quantity discounts on supply chain coordination [19]. These assumptions about the demand mean that there is no default risk for trade credit, which means the borrower can repay the credit loan certainly. In reality, however, the borrower cannot always repay the credit loan because of the bad sales. And this brings the default risk to lenders.

Considering the default risk coming from the probabilities of the supplier and the retailer's bankruptcy, Lee and Rhee (2011) applied a Newsvendor framework to study supply chain coordination using trade credit as a tool from the supplier's perspective [20]. For Lou and Wang (2013) and Wu et al. (2017), the optimal order quantity and credit period were discussed by assuming that the longer the credit period offered to the buyer, the higher the default risk to the seller $[21,22]$. Tsao (2018) extended this study to the uncertain default risk [23].

The uncertain demand is an important factor to the default risk and is common in business. Therefore, including uncertain demand is critical when analyzing trade credit in supply chain. Under an uncertain demand scenario, Chaharsooghi and Heydari (2010) and Arkan and Hejazi (2012) proposed incentive schemes to coordinate the supply chain $[24,25]$; Heydari (2015) then extended to truckload limitations [26]. Heydari et al. (2017) investigated how a two-level trade credit contributed to coordination under an assumed stochastic and credit-dependent demand [2]. Although these literatures above assumed an uncertain demand, the default risk coming from this uncertain demand under trade credit was not considered.

Considering the default risk coming from the uncertain demand, Kouvelis and Zhao (2012) analyzed a retailer's optimal decisions when seeking a loan from the supplier or from a bank and a supplier's optimal contract parameters [27]. Chen (2015) concluded that the trade credit made both channel members better off, and there was a unique financing equilibrium in wholesale price contracts when retailers were confronted with capital constraints [28]. No more literatures, which consider the default risk coming from the uncertain demand, are found. But the assumption about uncertain demand in supply chain is popular and is the base of newsvendor model. The default risk in credit trade always happens because of bad sales which is not as expected. So, considering the default risk with uncertain demand is necessary in trade credit study. 
To reduce the default risk, Yang et al. (2016) proposed a two-period model with a flexible trade credit contract to incentivize the retailer to settle the account early [29]. BigData analytics has also been proven to be a useful tool in reducing default risk; when the retailer (supplier) has the power to determine the credit period, the retailer (supplier) can implement Big-Data analytics [30]. In the presence of both retailer and supplier capital constraints, Kouvelis and Zhao (2012) [27] applied a supplier early payment discount scheme and concluded that both supplier and retailer preferred trade credit to bank financing. They also surmised that the reason not all suppliers wanted to offer cheap trade credits was because of symmetric information, such as an asymmetric ability to pay, asymmetric demand information, and asymmetric action about effort.

Asymmetric information is common in commercial activities. Ex ante asymmetric information is called adverse selection and ex post asymmetric information is known as moral hazard. Both adverse selection and moral hazard can be harmful. Therefore, the principal seeks to mitigate them. Using micro-data on Italian SMEs from 1998-2006, it was found that banks could use trade credit as the signal to offer additional loans to reduce asymmetric information [31]. However, there is also asymmetric information in trade credit. The adverse selection has been considered in previous studies, such as Wang (2018), in which the asymmetric credit default risk was discussed [32]. But moral hazard has not been widely considered. Therefore, this paper seeks to fill this gap by accounting for moral hazard.

With the mitigation of moral hazard in mind, some studies have designed incentive contracts under certain demand. Through the development of an agency model, Pindado (2007) found that in certain circumstances, trade credit was offered primarily to mitigate adverse selection rather than to mitigate moral hazard [33]. The question remains therefore as to whether the moral hazard under trade credit can be mitigated. Costello (2013) claimed that long-term rather than short-term contracts could better reduce moral hazard [34]. Csóka et al. (2015) proved that in the asymmetric case the borrowing capacity and the welfare of the society are weakly smaller than in the symmetric case by developing a game model [35]. In which discrete revenue was considered and trade credit was seen as similar to equity financing. Wang and Liu discussed the supply chain coordination under trade credit and moral hazard caused by retailer's private information about effort level [36]. They considered uncertain demand influenced by retailer's effort. But they did not consider the default risk from the uncertain demand.

Overall, from the perspective of supply chain management research, most literatures studying for trade credit adopt EOQ model and assumed constant market demand rate. And they also ignored the default risk for trade credit. A few existing papers focused on enhancing supply chain's efficiency and considered the default risk coming from the uncertain demand, which is a popular assumption in supply chain management. According to the authors' best knowledge, there have been few papers examining the moral hazard and default risk simultaneously in trade credit, under uncertain demand.
Therefore, in this paper, we construct principal-agent models based on newsvendor model to shed some light on the role of default risk and moral hazard in trade credit. This work is an extension of Chen (2015), which studied the trade credit contract considering default risk coming from the uncertain demand [28]. And moral hazard, because of retailer's private information of his sales effort, is introduced in this paper. Our work is distinguished from earlier studies as follows: (1) studying the impact of moral hazard on trade credit and (2) exploring the incentive contract to mitigate the impact of moral hazard. In addition, the decisions of retailers with different working capital are analyzed. At the same time, the condition when the manufacturer adopts the incentive contract is also studied.

\section{Model Description}

3.1. Assumptions and Notations. Most of the assumptions and notations are based on Wang and Liu (2018) [36], except the default risk coming from the trade credit. A supply chain with a risk-neutral manufacturer and a risk-neutral retailer is considered. The retailer purchases a single product from the manufacturer. The manufacturer dominates and first sets trade credit contract menu. Then, the retailer chooses the contract and executes his effort according to contract terms and market situation. The retailer is capital constraint. He pays part of the transfer payment with his working capital and arranges to settle the remainder of the account at the end of the sales period, when ordering.

The retailer faces the uncertain market demand. We assume the demand without sales effort effect is $y$ with a cumulative distribution function $F(y)$ and a probability density function $f(y)$. The market demand is affected by the retailer's effort, such as the promotion, maintaining and developing customers, etc. To model retailer's effort, supposing a single effort level, $e$, summarizes the retailer's activities and let $\psi(e)$ be the retailer's cost of exerting effort level $e$, where $\psi(e)=0 \psi^{\prime}(e)>0$ and $\psi^{\prime \prime}(e)>0$; let $F(y \mid e)$ be the distribution of demand given the retailer's sales effort level $e$, where demand is stochastically increasing in effort, i.e., $F_{e}(y \mid e)<0, F_{e e}(y \mid e)>0[8]$.

Because of the uncertain demand, the retailer's sales revenue is uncertain. If the retailer's sales revenue is sufficient to settle the account at the end of the sales period the manufacturer recovers the balance due; otherwise, the manufacturer receives all the retailer's sales revenue but is unable to recover the remaining debt because of the retailer's limited liability.

Finally, to focus on trade credit and incentive strategies, assume the product is seasonal product and neglect the salvage value of unsold items. The time value of the capital is also not considered.

The following notations are used throughout this study.

$p$ is the retailer's unit product retail price;

$c$ is the manufacturer's unit product production cost;

$\eta$ is working capital of the retailer;

$t$ is total transfer payments from retailer to manufacturer;

$w$ is the unit product wholesale price provided by manufacturer; 


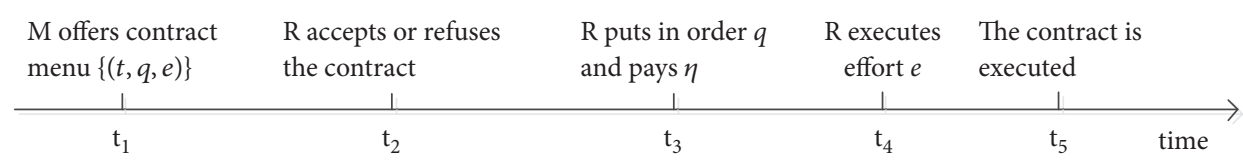

Figure 1: The sequence of events.

$q$ is ordering quantity of the retailer;

$e$ is sales effort level of the retailer;

$\pi_{s}$ is manufacturer's expected profit;

$\pi_{r}$ is retailer's expected profit;

$\pi$ supply chain's expected profit.

$e$ is retailer's decision variable. $t$ and $q$ are manufacturer's decision variables and constitute the contract provided by manufacturer.

3.2. The Basic Model. The manufacturer grants trade credit to the retailer and finances the retailer's purchase. The sequence of events is illustrated in Figure 1, in which M represents the manufacturer and $\mathrm{R}$ represents the retailer. Before making a transaction, the manufacturer provides a contract menu $\{(t, q, e)\}$, which the retailer can accept or reject. Then, the retailer chooses to accept or reject the contract menu. If the retailer refuses it, the transaction ends. If the retailer accepts it, he will put in order $q$ and pay $\eta$, leaving an account $t-\eta$ paid at the end of the sales period. The retailer executes effort $e$ during the sales period according to the contractual requirements. At the end of the sales period, both the manufacturer and retailer execute the contract. If there is adequate sales revenue to pay the account, the manufacturer can recycle $t-\eta$ owed by the retailer. Otherwise, the manufacturer receives all sales revenue $p y$ from the retailer and the retailer goes bankrupt.

When the sales revenue of the retailer is enough to cover the credit account, there is $p y \geq t-\eta$ which can be written as $y \geq(t-\eta) / p$. Therefore, when $y \geq(t-\eta) / p$, the retailer repays the full credit $t-\eta$ to the manufacturer, and when $y<(t-\eta) / p$ the retailer pays all sales revenue $p y$ to the manufacturer and declares bankrupt. Comprehending the above, the manufacturer takes default risk, and his expected profit function is

$$
\pi_{s}=t(q, e)-c q-\int_{0}^{z} p F(y \mid e) d y
$$

where $z=(t-\eta) / p$.

The retailer's expected profit function is

$$
\pi_{r}=p q-\int_{z}^{q} p F(y \mid e) d y-t(q, e)-\psi(e)
$$

The expected profit function of the integrated supply chain is

$$
\pi=p q-\int_{0}^{q} p F(y \mid e) d y-c q-\psi(e)
$$

Subsequently, the second partial derivatives of function (3) are $-p f(q \mid e)$ and $-\psi^{\prime \prime}(e)$, and both of them are not more than zero. With the assumption $p f(q \mid e) \int_{0}^{q} p F_{e e}(y \mid$ $e) d y+p f(q \mid e) \psi^{\prime \prime}(e)-p^{2} F_{e}^{2}(q \mid e)>0$, which is implied in Cachon with the same profit function and model of the supply chain [37], the Hessian matrix of the binary function $\pi(q, e)$ is positive. Thus, from the supply chain perspective, the optimal quantity and effort level $\left(q^{o}, e^{o}\right)$ can be solved from the following first order condition (4) and (5).

$$
\begin{array}{r}
-\int_{0}^{q^{o}} p F_{e^{o}}\left(y \mid e^{o}\right) d y-\psi^{\prime}\left(e^{o}\right)=0 \\
p \bar{F}\left(q^{o} \mid e^{o}\right)-c=0
\end{array}
$$

And the expected profit of the supply chain is

$$
\pi\left(q^{o}, e^{o}\right)=p q^{o}-\int_{0}^{q^{o}} p F\left(y \mid e^{o}\right) d y-c q^{o}-\psi\left(e^{o}\right)
$$

\section{The Model under Symmetric Information}

In this part, we assume the retailer's effort level can be observed and verified by the manufacturer. The observable and verifiable effort is contractual and enforceable. Therefore, the effort can be signed in the contract designed by the manufacturer to maximize his own profit.

From the sequence as Figure 1, the model of the manufacturer can be written as P1 based on the incentive theory.

$$
\begin{aligned}
\mathrm{P} 1: \underset{(t, q, e)}{\pi_{s}} & =t(q, e)-c q-\int_{0}^{z} p F(y \mid e) d y \\
\text { s.t. } \quad & \pi_{r} \geq \pi_{r 0}
\end{aligned}
$$

where $\pi_{r 0}$ is the retailer's reserved profit, which indicates that the retailer can get profit $\pi_{r 0}$ when participating other activities instead of this transaction. The constraint means that the retailer cannot receive more profit in some other activities than in this transaction.

Solving model P1 and Proposition 1 can be got as follows.

Proposition 1. Under symmetry information, the contract is $\left(t_{1}\left(q^{o}, e^{o}\right), q^{o}, e^{o}\right)$, where $t_{1}\left(q^{o}, e^{o}\right)=p q^{o}-\int_{z^{o}}^{q^{o}} p F\left(y \mid e^{o}\right) d y-$ $\psi\left(e^{o}\right)-\pi_{r 0}$. With this contract, the retailer retains the reserved profit $\pi_{r 0}$, and the manufacturer receives all other residual profit of the supply chain $\pi_{s 1}=\pi\left(q^{o}, e^{o}\right)-\pi_{r 0}$.

Proof. As the manufacturer does not allow the retailer to earn more than reserved profit, the manufacturer makes the transfer payment $t(q, e)=p q-\int_{0}^{q} p F(y \mid e) d y-\psi(e)+$ $\int_{0}^{z} p F(y \mid e) d y-\pi_{r 0}$ to maximize his profit. With this transfer payment, the retailer's expected profit is

$$
\pi_{r 1}=\pi_{r 0}
$$


The manufacture's expected profit is $\pi=p q-\int_{0}^{q} p F(y \mid$ $e) d y-c q-\psi(e)$. This is the same as the expected profit function of the integrated supply chain. So, the manufacturer makes decision consistent with the integrated supply chain. And the same as the integrated supply chain, the optimal product transaction volume and the optimal effort are $q^{o}$ and $e^{o}$, respectively.

Therefore, the transfer payment function and the profits of both sides are as follows:

$$
t_{1}\left(q^{o}, e^{o}\right)=p q^{o}-\int_{z^{o}}^{q^{o}} p F\left(y \mid e^{o}\right) d y-\psi\left(e^{o}\right)-\pi_{r 0}
$$

where $z^{o}=\left(t_{1}\left(q^{o}, e^{o}\right)-\eta\right) / p$.

$$
\begin{aligned}
& \pi_{r 1}=\pi_{r 0} \\
& \pi_{s 1}=\pi\left(q^{o}, e^{o}\right)-\pi_{r 0}
\end{aligned}
$$

The retailer only retains the reserved profits $\pi_{r 0}$, and the manufacturer receives the full residual supply chain profit $\pi_{s 1}=\pi\left(q^{o}, e^{o}\right)-\pi_{r 0}$.

From Proposition 1, we can find that the order quantity, the effort level, and expected profits of both partners have no relationship with the retailer's working capital. Only the total transfer payment is influenced by the retailer's working capital.

Property 2. The transfer payment $t_{1}\left(q^{o}, e^{o}\right)$ decreases with an increase in $\eta$.

Proof. From (9), we can get $\partial t_{1}\left(q^{o}, e^{o}\right) / \partial \eta=-F\left(z^{o} \mid e^{o}\right) /(1-$ $\left.F\left(z^{o} \mid e^{o}\right)\right) . F\left(z^{o} \mid e^{o}\right)$ is a cumulative distribution function and is no bigger than 1 . So, $\partial t_{1}\left(q^{o}, e^{o}\right) / \partial \eta<0$, which means that the transfer payment $t_{1}\left(q^{o}, e^{o}\right)$ decreases with an increase in $\eta$.

Property 2 means that the retailer with higher working capital will pay less total transfer payment. This is because the retailer with higher working capital brings less default risk to the manufacturer.

\section{The Model under Asymmetric Information}

5.1. The Moral Hazard. Under asymmetric information, we assume that the retailer's effort level is his private information. The true effort level of the retailer cannot be observed and verified by the manufacturer or any other third party. And a contract binding the retailer to choose a particular effort level cannot be signed.

In this case, if the manufacturer provides the same contract $\left(t_{1}\left(q^{o}, e^{o}\right), q^{o}, e^{o}\right)$, the retailer will execute the required order quantity $q^{o}$ because it can be observed. But the retailer will execute his optimal effort $e_{2}^{*}$ to maximize his profit, instead of the required effort $e^{o}$ because it cannot be observed. Therefore, a moral hazard arises.
With asymmetric information and the contract $\left(t_{1}\left(q^{\circ}\right.\right.$, $\left.\left.e^{o}\right), q^{o}, e^{o}\right)$, the retailer's expected profit function is

$$
\pi_{r 2}=p q^{o}-\int_{z^{o}}^{q^{o}} p F(y \mid e) d y-t_{1}\left(q^{o}, e^{o}\right)-\psi(e)
$$

We take the partial derivatives of (12) and obtain $\partial^{2} \pi_{r 2} / \partial e^{2}=-\int_{z^{o}}^{q^{o}} p F_{e e}(y \mid e) d y-\psi^{\prime \prime}(e)$. In addition, with the assumption $-\int_{z^{\circ}}^{q^{o}} p F_{e e}(y \mid e) d y-\psi^{\prime \prime}(e) \leq 0$, according to the first-order conditions, the retailer's optimal effort $e_{2}{ }^{*}$ is the solution of the following equation:

$$
-\int_{z^{o}}^{q^{o}} p F_{e_{2}^{*}}\left(y \mid e_{2}^{*}\right) d y-\psi^{\prime}\left(e_{2}^{*}\right)=0
$$

The profits obtained by the retailer and the manufacturer, respectively, are

$$
\begin{aligned}
\pi_{r 2}= & p \int_{z^{o}}^{q^{o}}\left(F\left(y \mid e^{o}\right)-F\left(y \mid e_{2}^{*}\right)\right) d y+\psi\left(e^{o}\right) \\
& -\psi\left(e_{2}^{*}\right)+\pi_{r 0} \\
\pi_{s 2}= & \pi\left(q^{o}, e^{o}\right)+p \int_{0}^{z^{o}}\left(F\left(y \mid e^{o}\right)-F\left(y \mid e_{2}^{*}\right)\right) d y \\
& -\pi_{r 0}
\end{aligned}
$$

and the total profit of the supply chain is

$$
\begin{aligned}
\pi_{2} & =\pi\left(q^{o}, e^{o}\right)+p \int_{0}^{q^{o}}\left(F\left(y \mid e^{o}\right)-F\left(y \mid e_{2}^{*}\right)\right) d y \\
& +\psi\left(e^{o}\right)-\psi\left(e_{2}^{*}\right)
\end{aligned}
$$

We can get Proposition 3 as follows.

Proposition 3. Under asymmetric information and the contract $\left(t_{1}\left(q^{o}, e^{o}\right), q^{o}, e^{o}\right)$, the retailer's effort level $e_{2}^{*}$ is the solution to (13), and the expected profits of the retailer, manufacturer, and supply chain are (14), (15), and (16), respectively.

Property 4. There is $e_{2}^{*} \leq e^{o}$, and $e_{2}^{*}$ increases with $\eta$ increasing.

Proof. With the assumption $-\int_{z^{o}}^{q^{o}} p F_{e e}(y \mid e) d y-\psi^{\prime \prime}(e) \leq$ $0,-\int_{z^{o}}^{q^{o}} p F_{e}(y \mid e) d y-\psi^{\prime}(e)$ decreases with $e$ increasing. Equation (4) can be written as $-\int_{0}^{z^{o}} p F_{e^{o}}\left(y \mid e^{o}\right) d y-$ $\int_{z^{o}}^{q^{o}} p F_{e^{o}}\left(y \mid e^{o}\right) d y-\psi^{\prime}\left(e^{o}\right)=0$. If $e_{2}^{*}>e^{o}$, then $-\int_{z^{o}}^{q^{o}} p F_{e_{2}^{*}}(y \mid$ $\left.e_{2}^{*}\right) d y-\psi^{\prime}\left(e_{2}^{*}\right)<-\int_{z^{o}}^{q^{o}} p F_{e^{o}}\left(y \mid e^{o}\right) d y-\psi^{\prime}\left(e^{o}\right)$. Combining with (13), there is $-\int_{z^{o}}^{q^{o}} p F_{e^{o}}\left(y \mid e^{o}\right) d y-\psi^{\prime}\left(e^{o}\right)>0$. This means that (4) cannot be satisfied. So, there is $e_{2}^{*} \leq e^{o}$. The retailer exerts less effort under asymmetric information than that under symmetric information, which is in line with the moral hazard expectation.

From (13), we have $\left(-\int_{z^{o}}^{q^{o}} p F_{e_{2}^{*} e_{2}^{*}}\left(y \mid e_{2}^{*}\right) d y-\psi^{\prime \prime}\left(e_{2}^{*}\right)\right)\left(\partial e_{2}^{*} /\right.$ $\partial \eta)+F_{e_{2}^{*}}\left(z^{o} \mid e_{2}^{*}\right)\left(\partial t_{1} / \partial \eta-1\right)=0$. Combining Property 2 , we 
can get $\partial e_{2}^{*} / \partial \eta \geq 0 ; e_{2}^{*}$ increases with $\eta$. The retailer exerts more effort when he puts in more working capital.

Property 5. Under this situation, the retailer's profit $\pi_{r 2}$ decreases with an increase in $\eta$.

Proof. From (14) and (13), we can have $\partial \pi_{r 2} / \partial \eta=\left(F\left(z^{o}\right.\right.$ $\left.\left.e_{2}^{*}\right)-F\left(z^{o} \mid e^{o}\right)\right) /\left(F\left(z^{o} \mid e^{o}\right)-1\right)$. Because of $F_{e}(y \mid e)<0$ and $e_{2}^{*} \leq e^{o}$, there is $\partial \pi_{r 2} / \partial \eta \leq 0$. The retailer gets less profit when he has more working capital.

So, from Property 5 , the retailer can get more profit by reducing his effort level, when his working capital is small. But when the retailer has more working capital, he can get less profit by reducing his effort level. This means that moral hazard is more likely to happen, when $\eta$ is small.

Property 6. Under moral hazard, there is $\pi_{s 2} \leq \pi\left(q^{o}, e^{o}\right)$, and $\pi_{s 2}$ increases with an increase in $\eta$.

Proof. With Property 4, the retailer usually executes a lower effort level than the optimal effort to get more profit. Comparing (15) and (11), the reduce of effort causes a change $p \int_{0}^{z^{o}}\left(F\left(y \mid e_{2}{ }^{*}\right)-F\left(y \mid e^{o}\right)\right) d y$ to the manufacturer's profit. Because of $F_{e}(y \mid e) \leq 0$ and Property 4, $p \int_{0}^{z^{o}}\left(F\left(y \mid e_{2}^{*}\right)-\right.$ $\left.F\left(y \mid e^{o}\right)\right) d y \leq 0$. So, the manufacturer encounters profit loss $p \int_{0}^{z^{o}}\left(F\left(y \mid e_{2}^{*}\right)-F\left(y \mid e^{o}\right)\right) d y$ under asymmetric information and the contract $\left(t\left(q^{o}, e^{o}\right), q^{o}, e^{o}\right)$.

Because of $F_{e}(y \mid e) \leq 0$, it is easy to find that $p \int_{0}^{z^{o}}\left(F_{e}(y \mid\right.$ $e)) d y \leq 0$. So, the loss decreases with an increase in $e$. Combining this and Property 2, we come to a conclusion that the loss decreases with an increase in $\eta$. Therefore, the manufacturer's expected profit under moral hazard increases with an increase in $\eta$.

Combining Properties 5 and 6, the retailer with low working capital could get more profit by reducing effort level but brings more profit loss to the manufacturer. It is better for the manufacturer refusing the retailer with low working capital to reduce moral hazard and profit loss, under asymmetric information. However, trade credit is inevitable in modern commercial activities. When refusing the retailer with little capital is not feasible, the manufacturer needs to take other measures such as incentive contracts to reduce his losses from moral hazard.

5.2. Incentive Contract. To reduce the profit loss coming from the moral hazard, the manufacturer needs to encourage the retailer to improve effort level. The manufacturer's incentive model can be developed as P2.

$$
\begin{aligned}
\mathrm{P} 2: \max _{\{(t(q), q)\}} & \pi_{s}=t(q)-c q-\int_{0}^{z} p F(y \mid e) d y \\
\text { s.t. } \quad & e=\arg \max _{e} \pi_{r} \\
& \pi_{r} \geq \pi_{r 0}
\end{aligned}
$$

In constraints, arg max means arguments of the maxima [38]. Solved as $\mathrm{P} 1$, the transaction quantity $q_{3}^{*}$ and retailer's effort $e_{3}^{*}$ expected by the manufacturer in the contract are the solutions to the following equations:

$$
\begin{gathered}
-\int_{0}^{q_{3}^{*}} p F_{e_{3}^{*}}\left(y \mid e_{3}^{*}\right) d y-\psi^{\prime}\left(e_{3}^{*}\right) \\
+\int_{0}^{z_{3}^{*}} p F_{e_{3}^{*}}\left(y \mid e_{3}^{*}\right) d y=0 \\
p-p F\left(q_{3}^{*} \mid e_{3}^{*}\right)-c=0
\end{gathered}
$$

where $z_{3}^{*}=\left(t\left(q_{3}^{*}, e_{3}^{*}\right)-\eta\right) / p$, and

$$
\begin{aligned}
t\left(q_{3}^{*}, e_{3}^{*}\right)= & p q_{3}^{*}-\int_{0}^{q_{3}^{*}} p F\left(y \mid e_{3}^{*}\right) d y-\psi\left(e_{3}^{*}\right) \\
& +\int_{0}^{z_{3}^{*}} p F\left(y \mid e_{3}^{*}\right) d y-\pi_{r 0}
\end{aligned}
$$

With contract $\left(t\left(q_{3}^{*}, e_{3}^{*}\right), q_{3}^{*}, e_{3}^{*}\right)$, the respective profits for the supply chain, the manufacturer, and the retailer are as in (21), (22), and (23).

$$
\begin{aligned}
\pi_{3}\left(q_{3}^{*}, e_{3}^{*}\right)= & p q_{3}^{*}-\int_{0}^{q_{3}^{*}} p F\left(y \mid e_{3}^{*}\right) d y-\psi\left(e_{3}^{*}\right) \\
& -c q_{3}^{*} \\
\pi_{s 3}= & \pi\left(q_{3}^{*}, e_{3}^{*}\right)-\pi_{r 0} \\
\pi_{r 3}= & \pi_{r 0}
\end{aligned}
$$

Proposition 7. Under moral hazard, the incentive contract provided by the manufacturer is $\left(t\left(q_{3}^{*}, e_{3}^{*}\right), q_{3}^{*}, e_{3}^{*}\right)$, in which $q_{3}^{*}$ and $e_{3}^{*}$ are the solutions to (18) and (19), and the transfer payment $t\left(q_{3}^{*}, e_{3}^{*}\right)$ is determined by (20). Therefore, the respective profits of the supply chain, the manufacturer, and the retailer are (21), (22), and (23).

From Propositions 3 and 7, we can find that the retailer's profit is reduced to his reserved profit. And when $\pi\left(q^{o}, e^{o}\right)-$ $\pi\left(q_{3}^{*}, e_{3}^{*}\right) \leq \int_{0}^{z^{o}} p F\left(y \mid e_{2}^{*}\right) d y-\int_{0}^{z^{o}} p F\left(y \mid e^{o}\right) d y$ is satisfied the manufacturer obtains a higher profit with the incentive contract and the incentive contract is adopted to prevent the moral hazard. Otherwise, the manufacturer obtains a higher profit without an incentive contract and he will accept the profit loss coming from moral hazard instead of adopting incentive measures. Therefore, the inequality can be used to assess whether the manufacturer chooses to take the incentive measure. We can get Property 8 as follows.

Property 8. If $\pi\left(q^{o}, e^{o}\right)-\pi\left(q_{3}^{*}, e_{3}^{*}\right) \leq \int_{0}^{z^{o}} p F\left(y \mid e_{2}^{*}\right) d y-$ $\int_{0}^{z^{o}} p F\left(y \mid e^{o}\right) d y$ is satisfied, the manufacturer adopts the incentive contract to motivate the retailer; otherwise the manufacturer does not adopt the incentive contract.

The left part of $\pi\left(q^{o}, e^{o}\right)-\pi\left(q_{3}^{*}, e_{3}^{*}\right) \leq \int_{0}^{z^{o}} p F(y$ $\left.e_{2}^{*}\right) d y-\int_{0}^{z^{o}} p F\left(y \mid e^{o}\right) d y$ is the profit loss of supply chain 


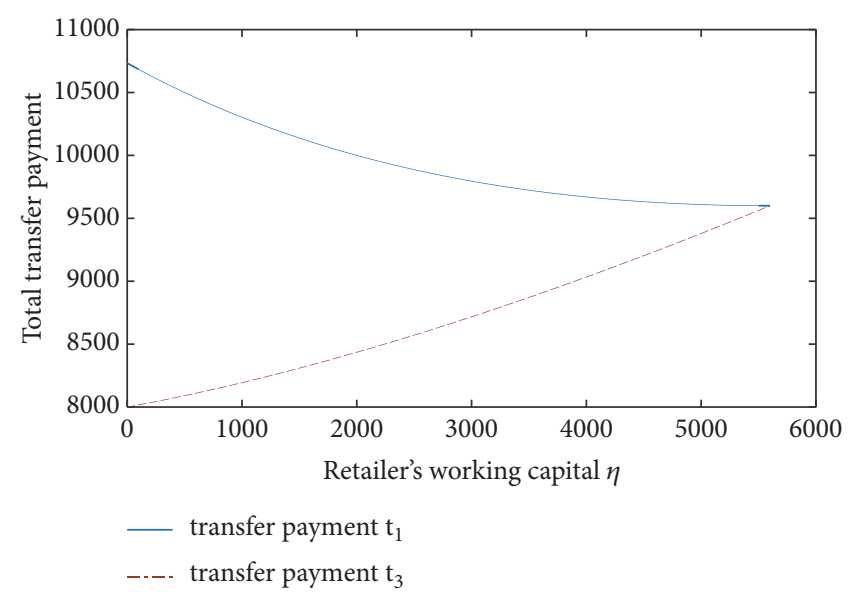

FIGURE 2: Change trend of total transfer payment with retailer's working capital $\eta$.

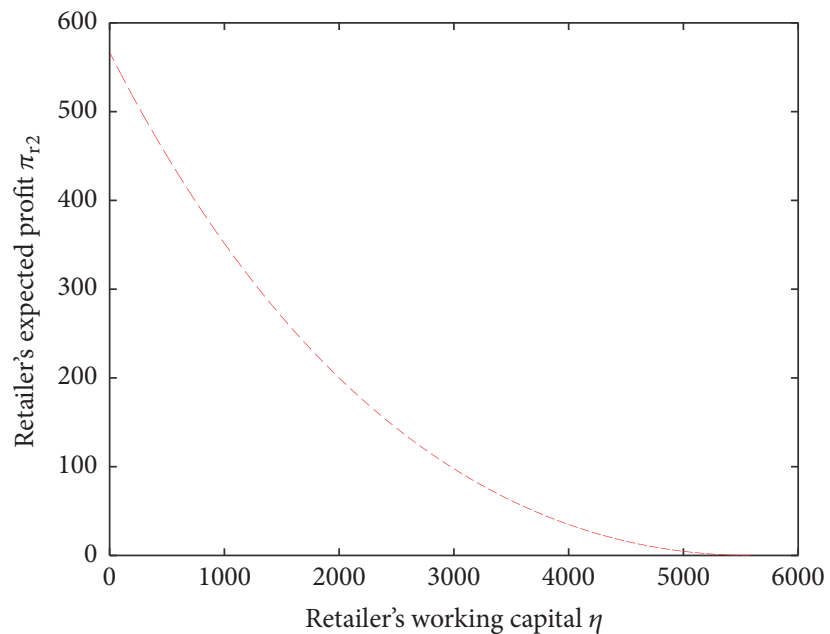

FIGURE 3: Change trend of retailer's expected profit $\pi_{r 2}$ with retailer's working capital $\eta$.

comparing with profit under symmetric information. And the right part is the losses of unmarketable products increased by reducing retailer's effort. Therefore, under asymmetric information, if the profit loss of supply chain under incentive is lower than the unmarketable losses increased with moral hazard, the manufacturer is willing to take the incentive measures. Otherwise, the manufacturer tolerates the moral hazard rather than taking any incentive measures.

\section{An Illustrating Example}

We now employ numerical examples to further analyze the model under symmetric information and asymmetric information. In the supply chain configuration, we suppose that $p=80, c=40$; assume the retailer's effort cost follows $\psi(e)=e^{2} / 2$ [37]; let the market demand with retailer's effort effects be $y$ and $y$ is subject to uniform distribution, that is, $y \sim U(e, e+200)$; let the retailer's reserved profit $\pi_{r 0}=0$.

At first, we analyze the optimal order quantity and effort level of the integrated supply chain. The Hessian matrix of the binary function $\pi(q, e)$ is $|H|=1 / 2>0$. And there are $\partial^{2} \pi / \partial e^{2}=-3 / 2<0$ and $\partial^{2} \pi / \partial e^{2}=-1 / 2<0$. Therefore, according to optimization theory, $\pi(q, e)$ has the only optimal solution $\left(\left(q^{o}, e^{o}\right)=(120,40)\right.$ as the order quantity and effort level, and the profit of the supply chain is 2400 .

Then, we consider the symmetric information. Under this situation, the retailer gets zero profit and the manufacturer gets all supply chain's profit 2400 . The contract is $\left(t_{1}\left(q^{o}, e^{o}\right), q^{o}, e^{o}\right)$ and the total transfer payment is shown in Figure 2 , when $\eta \leq 5600$. The total transfer payment increases with retailer's working capital decreasing, which is described in Property 2. When $\eta \geq 5600$, there is $(t-\eta) / p \leq e^{o}$, which means there is no default risk to the manufacturer and the retailer can pay all the account $t-\eta$ under the demand $e^{o}$. And when $\eta \geq 5600$, the total transfer payment is 9600 .

At last, we consider the situation with asymmetric information. When the manufacturer asks for quantity and effort level $\left(q^{o}, e^{o}\right)=(120,40)$ in the contract, the retailer will order quantity $q^{o}$ and exert effort level $e_{2}^{*}$ instead of $e^{o}$ to get profit $\pi_{r 2}$ which is more than zero. As seen in Figure 3 and described in Property 5, the retailer's expected profit decreases with his working capital increasing, when he exerts effort level $e_{2}^{*}$. 


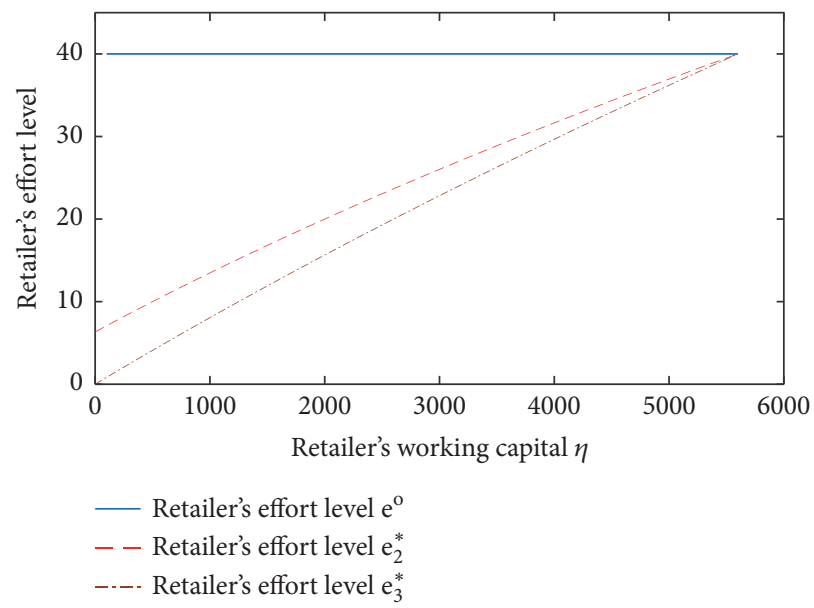

FIGURE 4: Change trend of retailer's effort level with retailer's working capital $\eta$.

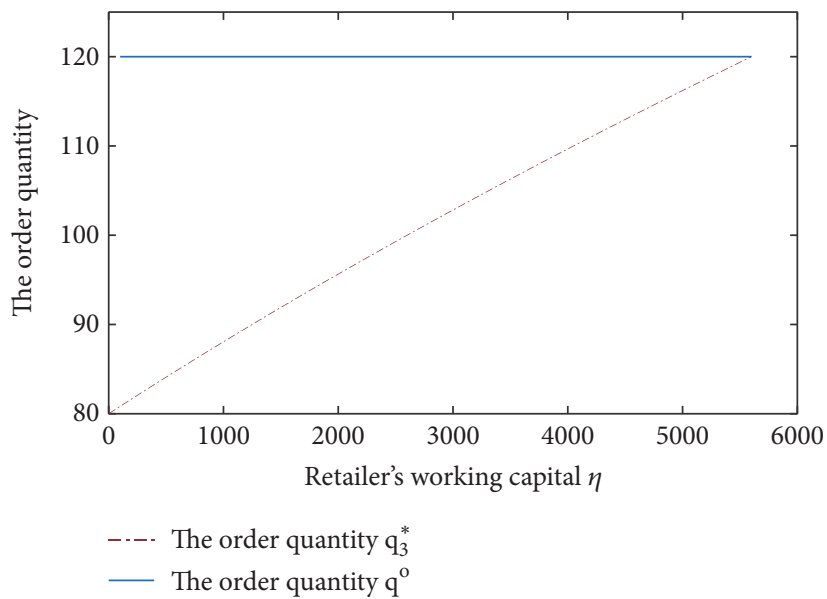

FIGURE 5: Change trend of order quantity with retailer's working capital $\eta$.

When $\eta \geq 5600$, the manufacturer has no default risk, so the retailer's expected profit is zero.

We can draw retailer's effort level $e_{2}^{*}$ and $e^{o}$ in Figure 4. As concluded in Property 4, Figure 4 shows that $e_{2}^{*}$ is lower than $e^{o}$ and increases with $\eta$ increasing when $\eta<5600$. This is because the default risk is shared by the manufacturer. And when all default risk is taken by the retailer, which means $\eta \geq$ 5600, he will exert effort level $e^{o}$.

Under the situation with asymmetric information, if the manufacturer takes incentive contract, the retailer's effort level $e_{3}^{*}$ is shown in Figure 4 and the order quantity $q_{3}^{*}$ is shown in Figure 5. The retailer's effort level $e_{3}^{*}$ increases with his working capital increasing. But it is lower than the optimal effort level $e^{o}$ and the effort level $e_{2}^{*}$. The order quantity $q_{3}^{*}$ increases with retailer's working capital increasing and is below the optimal order quantity. When the manufacturer takes no default risk, effort level is $e^{o}$ and the order quantity is $q^{o}$.

As seen in Figure 6, the manufacturer's expected profit increases with an increase in retailer's working capital $\eta$, under the situation with asymmetric information. This means that the manufacturer's loss caused by moral hazard decreases with an increase in $\eta$. These are described in Properties 5 and 6.

The manufacturer can get more profit when he takes incentives contract. And this increased profit comes from the order quantity reduced as seen in Figure 5. When the manufacturer takes no default risk, he gets all the profit of the supply chain under both the moral hazard and the incentive contract.

\section{Conclusions}

Trade credit is widespread for financing in commercial activities. And it is also an important issue in supply chain management. Like a double-edged sword, trade credit has been shown to be good for the supply chain but also results in default risks to the manufacturer and even supply chain crisis. Much literature in supply chain management has studied the retailer's stocking policies and the manufacturer's trade credit contracts. Only a few papers studied trade credit considering 


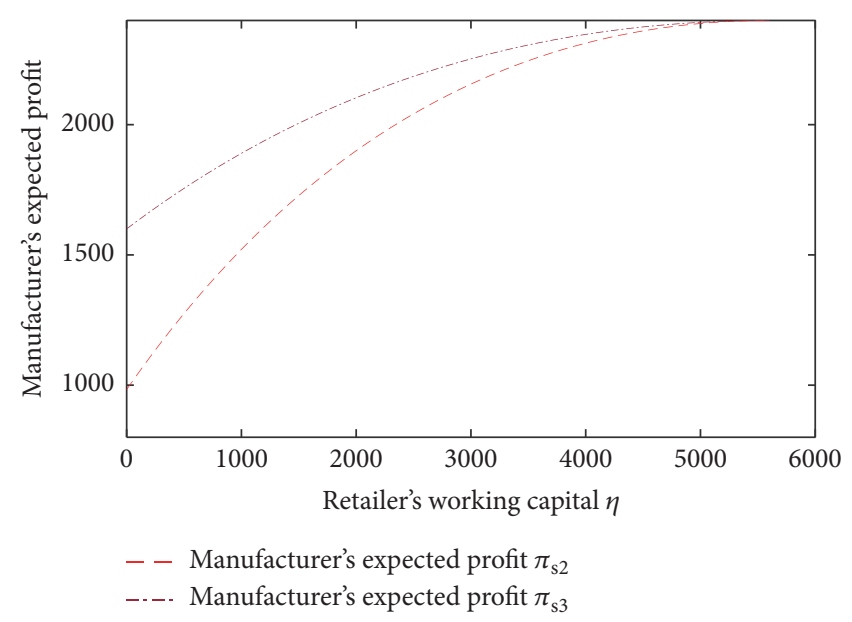

FIGURE 6: Change trend of manufacturer's expected profit with retailer's working capital $\eta$.

the default risk, and few papers combined the default risk and moral hazard.

This research sheds light on trade credit study in supply chain management with default risk and moral hazard. The default risk is coming from the uncertain market influenced by retailer's sale effort. Retailer's effort level is his private information. The principal-agent models are developed using incentive theory in a newsvendor framework, under the situation of symmetric information and the situation of asymmetric information separately. By model analysis and numerical examples, some conclusions and managerial implications are obtained as follows.

Under the situation of symmetric information, the order quantity, the sales effort, and the profit of the whole supply chain are the same as those in the integrated supply chain. The retailer only retains the reserved profit, and the manufacturer gets all other residual profit of the supply chain by an incentive transfer payment which decreases with an increase in retailer's working capital. The manufacturer should ask more transfer payment when the retailer has less working capital because less working capital means more default risk.

Under the situation of asymmetric information, the retailer pays less sales effort than what he pays under the symmetric information. Without the incentive contract, we can find that the retailer's sales effort increases with an increase in his working capital, but the retailer's profit decreases with an increase in his working capital. At the same time, the manufacturer's profit increases with an increase in the retailer's working capital. This means that when the effort level cannot be observed by the manufacturer, by reducing his effort level, the retailer can get more profit than the residual profit. And the retailer with less working capital can get more profit by executing less effort. This action brings profit loss to the manufacturer. It is better for the manufacturer refusing the retailer with low working capital, to avoid serious moral hazard and profit loss.

By an incentive model, it is found that the order quantity is lowered in the incentive contract to mitigate the impact of moral hazard. And under certain condition the manufacturer can take incentive contract and reduce the order quantity to improve his profit. Specifically, if the profit loss of supply chain by reducing the order quantity is lower than the unmarketable losses by keeping the optimal quantity in contract, the manufacturer should take the incentive measures. Otherwise, the manufacturer should tolerate the moral hazard instead of taking any incentive measures. Furthermore, if the retailer has sufficient working capital, the manufacturer will have no default risk and is advised to take no incentive.

We have considered a supply chain with a risk-neutral manufacturer and a risk-neutral retailer. Nevertheless, the supply chain may consist of multiple retailers and multiple suppliers. What influence does the competition among multiple retailers have on the trade credit? Will the impact of the moral hazard be reduced by the competition? Is there a need for the incentive contract for the manufacturer? the assumption of risk-neutral should also be relaxed, and channel partner's different attitudes toward risk will be considered. For instance, the model can be extended to study the willingness of the risk-aversion manufacturer.

Only retailer's sales effort, which influences the uncertain demand and is his private information, is considered in this research. The manufacturer can also influence the market demand by his promotional activities. And the true effort and cost of these activities are the manufacturer's private information. This means that the moral hazard may be caused by the manufacturer's private information. This case calls for a new incentive scheme to make the retailer accept the contract menu. And this study would be extended to the bilateral moral hazard, in which situation both the retailer and the manufacturer have private information influencing the uncertain demand. The bilateral incentive model may be needed to reduce both the retailer's unsold risk and the manufacturer's default risk.

Another extension would be to introduce the Pareto improving to the incentive contract. In this paper, we design the incentive mechanism and seek the incentive contract to mitigate the impact of moral hazard. It is necessary and has 
bothered us for a long time how should Pareto improving be introduced to the incentive mechanism.

In addition, we may extend this framework to the multistage trade credit. If the retailer cannot pay the account at the first stage because of the bad sales, should the manufacturer provide trade at the second stage to recover the remaining debt of the first stage? This is interesting and is helpful to manufacturers who have bad account because of trade credit.

\section{Data Availability}

The data used to support the findings of this study are available from the corresponding author upon request.

\section{Conflicts of Interest}

All the authors declare that they have no conflict of any competing financial, professional, or personal interests with other parties.

\section{Acknowledgments}

This work was supported by the MOE (Ministry of Education in China) Project of Humanities and Social Sciences [Grant no. 14YJC630020]; Sichuan Science and Technology Program [Grant.no. 2019JDR0210]; the National Natural Science Foundation of China [Grant nos. 71502037, 71501019]; Chengdu University of Technology [Grant no. KYTD201406]; and Sichuan University [Grant no skqy201768].

\section{References}

[1] Y. Zhong, J. Shu, W. Xie, and Y.-W. Zhou, "Optimal trade credit and replenishment policies for supply chain network design," OMEGA - The International Journal of Management Science, vol. 81, pp. 26-37, 2018.

[2] J. Heydari, M. Rastegar, and C. H. Glock, "A two-level delay in payments contract for supply chain coordination: The case of credit-dependent demand," International Journal of Production Economics, vol. 191, pp. 26-36, 2017.

[3] P. Pramanik, M. K. Maiti, and M. Maiti, "A supply chain with variable demand under three level trade credit policy," Computers \& Industrial Engineering, vol. 106, pp. 205-221, 2017.

[4] D. Fabbri and L. F. Klapper, "Bargaining power and trade credit," Journal of Corporate Finance, vol. 41, pp. 66-80, 2016.

[5] S. Carbó-Valverde, F. Rodríguez-Fernández, and G. F. Udell, "Trade credit, the financial crisis, and sme access to finance," Journal of Money, Credit and Banking, vol. 48, no. 1, pp. 113-143, 2016.

[6] L.-H. Chen and F.-S. Kang, "Coordination between vendor and buyer considering trade credit and items of imperfect quality," International Journal of Production Economics, vol. 123, no. 1, pp. 52-61, 2010.

[7] D. Chor and K. Manova, "Off the cliff and back? Credit conditions and international trade during the global financial crisis," Journal of International Economics, vol. 87, no. 1, pp. 117133, 2012.

[8] G. P. Cachon, "Supply chain coordination with contracts," Handbooks in Operations Research and Management Science, vol. 11, pp. 227-340, 2003.
[9] S. K. Goyal, "Economic order quantity under conditions of permissible delay in payments," Journal of the Operational Research Society, vol. 36, no. 4, pp. 335-338, 1985.

[10] S. P. Aggarwal and C. K. Jaggi, "Ordering policies of deteriorating items under permissible delay in payments," Journal of the Operational Research Society, vol. 46, no. 5, pp. 658-662, 1995.

[11] J.-T. Teng, "Optimal ordering policies for a retailer who offers distinct trade credits to its good and bad credit customers," International Journal of Production Economics, vol. 119, no. 2, pp. 415-423, 2009.

[12] S. Tiwari, L. E. Cárdenas-Barrón, M. Goh, and A. A. Shaikh, "Joint pricing and inventory model for deteriorating items with expiration dates and partial backlogging under two-level partial trade credits in supply chain," International Journal of Production Economics, vol. 200, pp. 16-36, 2018.

[13] F. Lin, T. Jia, F. Wu, and Z. Yang, "Impacts of two-stage deterioration on an integrated inventory model under trade credit and variable capacity utilization," European Journal of Operational Research, vol. 272, no. 1, pp. 219-234, 2019.

[14] L. Feng and Y.-L. Chan, "Joint pricing and production decisions for new products with learning curve effects under upstream and downstream trade credits," European Journal of Operational Research, vol. 272, no. 3, pp. 905-913, 2019.

[15] K.-J. Chung, L. Eduardo Cárdenas-Barrón, and P.-S. Ting, “An inventory model with non-instantaneous receipt and exponentially deteriorating items for an integrated three layer supply chain system under two levels of trade credit," International Journal of Production Economics, vol. 155, pp. 310-317, 2014.

[16] J.-J. Liao, K.-N. Huang, K.-J. Chung, P.-S. Ting, S.-D. Lin, and H. M. Srivastava, "Lot-sizing policies for deterioration items under two-level trade credit with partial trade credit to credit-risk retailer and limited storage capacity," Mathematical Methods in the Applied Sciences, vol. 40, no. 6, pp. 2122-2139, 2017.

[17] S.-M. Hosseini-Motlagh, M. Nematollahi, M. Johari, and B. R. Sarker, "A collaborative model for coordination of monopolistic manufacturer's promotional efforts and competing duopolistic retailers' trade credits," International Journal of Production Economics, vol. 204, pp. 108-122, 2018.

[18] J. Luo, "Buyer-vendor inventory coordination with credit period incentives," International Journal of Production Economics, vol. 108, no. 1-2, pp. 143-152, 2007.

[19] S. Yang, K.-S. Hong, and C. Lee, "Supply chain coordination with stock-dependent demand rate and credit incentives," International Journal of Production Economics, vol. 157, no. 1, pp. 105-111, 2014.

[20] C. H. Lee and B.-D. Rhee, "Trade credit for supply chain coordination," European Journal of Operational Research, vol. 214, no. 1, pp. 136-146, 2011.

[21] K.-R. Lou and W.-C. Wang, "Optimal trade credit and order quantity when trade credit impacts on both demand rate and default risk," Journal of the Operational Research Society, vol. 64, no. 10, pp. 1551-1556, 2013.

[22] C. Wu, Q. Zhao, and M. Xi, "A retailer-supplier supply chain model with trade credit default risk in a supplier-Stackelberg game," Computers \& Industrial Engineering, vol. 112, pp. 568$575,2017$.

[23] Y.-C. Tsao, "Trade credit and replenishment decisions considering default risk," Computers \& Industrial Engineering, vol. 117, pp. 41-46, 2018.

[24] S. K. Chaharsooghi and J. Heydari, "Supply chain coordination for the joint determination of order quantity and reorder point 
using credit option," European Journal of Operational Research, vol. 204, no. 1, pp. 86-95, 2010.

[25] A. Arkan and S. R. Hejazi, "Coordinating orders in a two echelon supply chain with controllable lead time and ordering cost using the credit period," Computers \& Industrial Engineering, vol. 62, no. 1, pp. 56-69, 2012.

[26] J. Heydari, "Coordinating replenishment decisions in a twostage supply chain by considering truckload limitation based on delay in payments," International Journal of Systems Science, vol. 46, no. 10, pp. 1897-1908, 2015.

[27] P. Kouvelis and W. Zhao, "Financing the newsvendor: supplier vs. bank, and the structure of optimal trade credit contracts," Operations Research, vol. 60, no. 3, pp. 566-580, 2012.

[28] X. Chen, "A model of trade credit in a capital-constrained distribution channel," International Journal of Production Economics, vol. 159, pp. 347-357, 2015.

[29] H. Yang, W. Zhuo, Y. Zha, and H. Wan, "Two-period supply chain with flexible trade credit contract," Expert Systems with Applications, vol. 66, pp. 95-105, 2016.

[30] Y.-C. Tsao, "Managing default risk under trade credit: Who should implement Big-Data analytics in supply chains?" Transportation Research Part E: Logistics and Transportation Review, vol. 106, pp. 276-293, 2017.

[31] M. Agostino and F. Trivieri, "Does trade credit play a signalling role? Some evidence from SMEs microdata," Small Business Economics, vol. 42, no. 1, pp. 131-151, 2014.

[32] K. Wang, R. Zhao, and J. Peng, "Trade credit contracting under asymmetric credit default risk: screening, checking or insurance," European Journal of Operational Research, vol. 266, no. 2, pp. 554-568, 2018.

[33] R. Bastos and J. Pindado, "An agency model to explain trade credit policy and empirical evidence," Applied Economics, vol. 39, no. 20, pp. 2631-2642, 2007.

[34] A. M. Costello, "Mitigating incentive conflicts in inter-firm relationships: Evidence from long-term supply contracts," Journal of Accounting and Economics, vol. 56, no. 1, pp. 19-39, 2013.

[35] P. Csóka, D. Havran, and N. Csóka, "Corporate financing under moral hazard and the default risk of buyers," Central European Journal of Operations Research, vol. 23, no. 4, pp. 763-778, 2015.

[36] Z. Wang and S. Liu, "Supply chain coordination under trade credit and quantity discount with sales effort effects," Mathematical Problems in Engineering, vol. 2018, Article ID 2190236, 15 pages, 2018.

[37] J. Heydari and J. Asl-Najafi, "A revised sales rebate contract with effort-dependent demand: a channel coordination approach," International Transactions in Operational Research, pp. 1-32, 2018.

[38] Z. Lin, C. Cai, and B. Xu, "Supply chain coordination with insurance contract," European Journal of Operational Research, vol. 205, no. 2, pp. 339-345, 2010. 


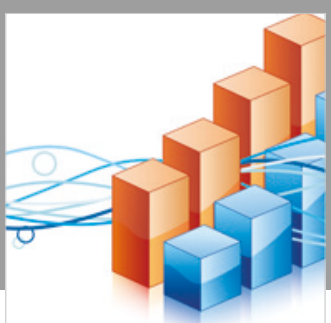

Advances in

Operations Research

\section{-n-m}
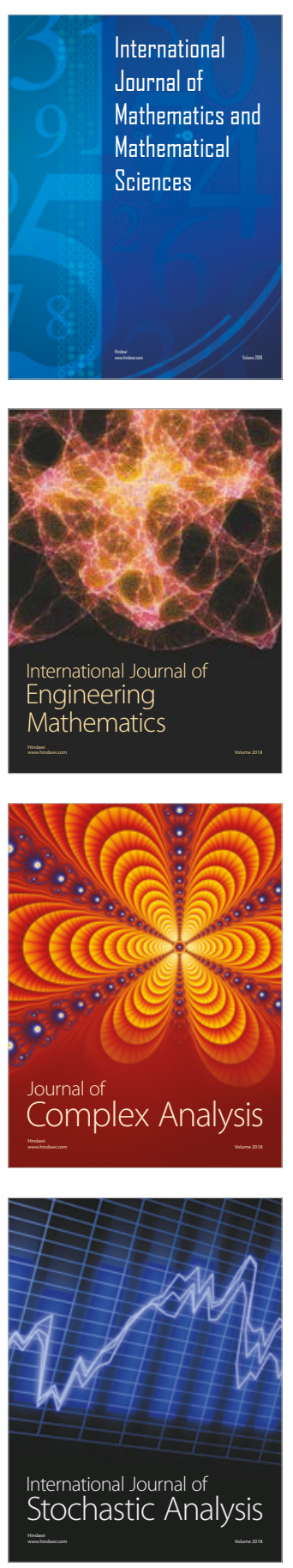
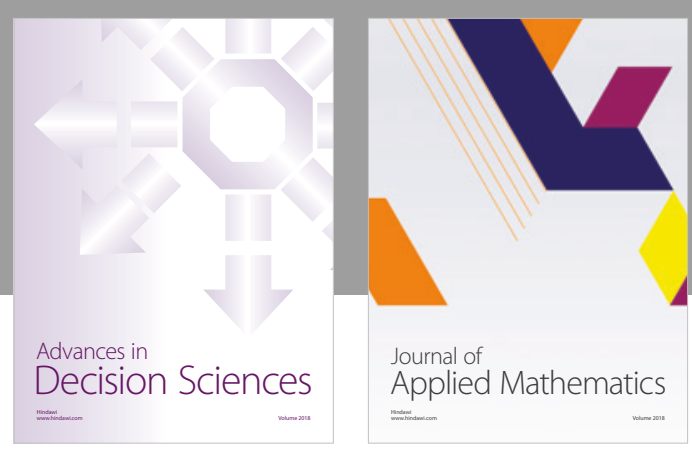

Journal of

Applied Mathematics
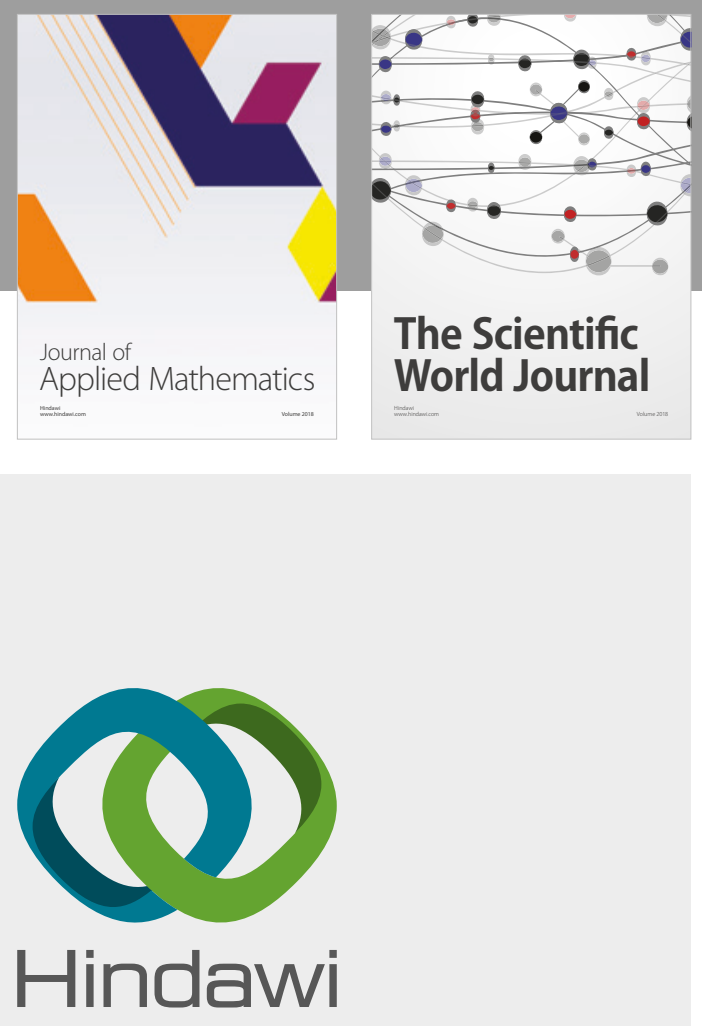

Submit your manuscripts at

www.hindawi.com

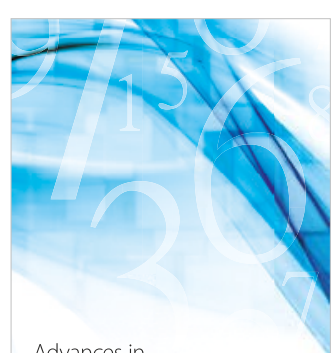

Advances in
Numerical Analysis
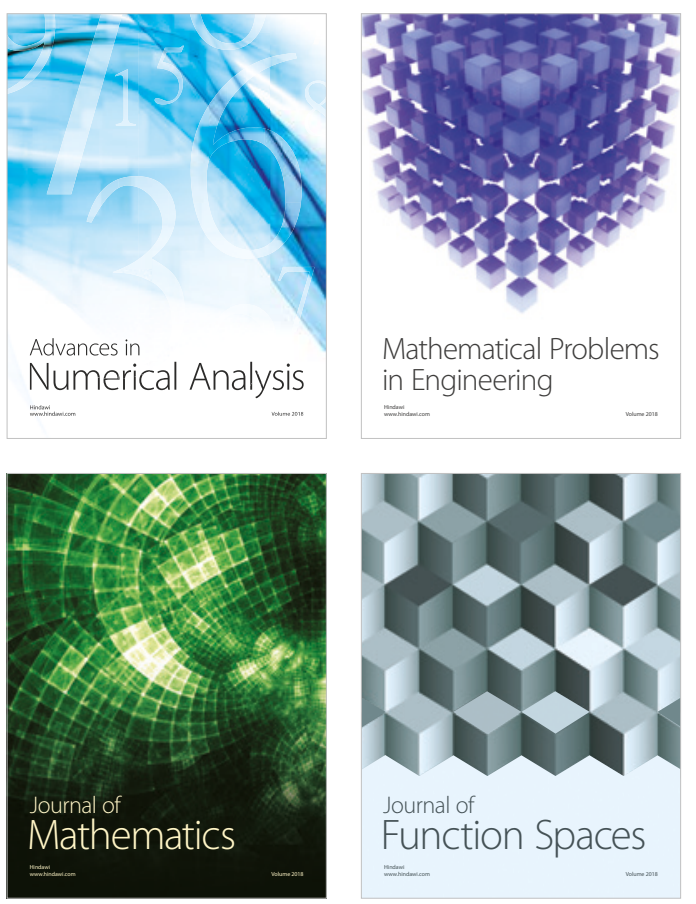

Mathematical Problems in Engineering

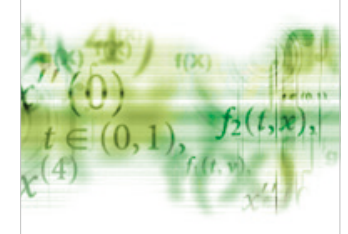

International Journal of

Differential Equations

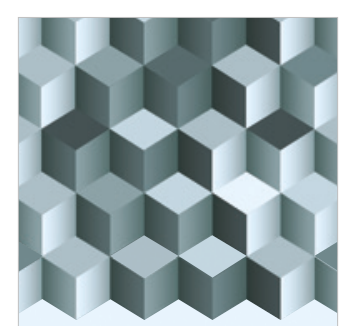

Journal of

Function Spaces
The Scientific

World Journal

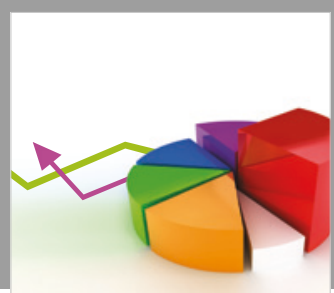

Journal of

Probability and Statistics
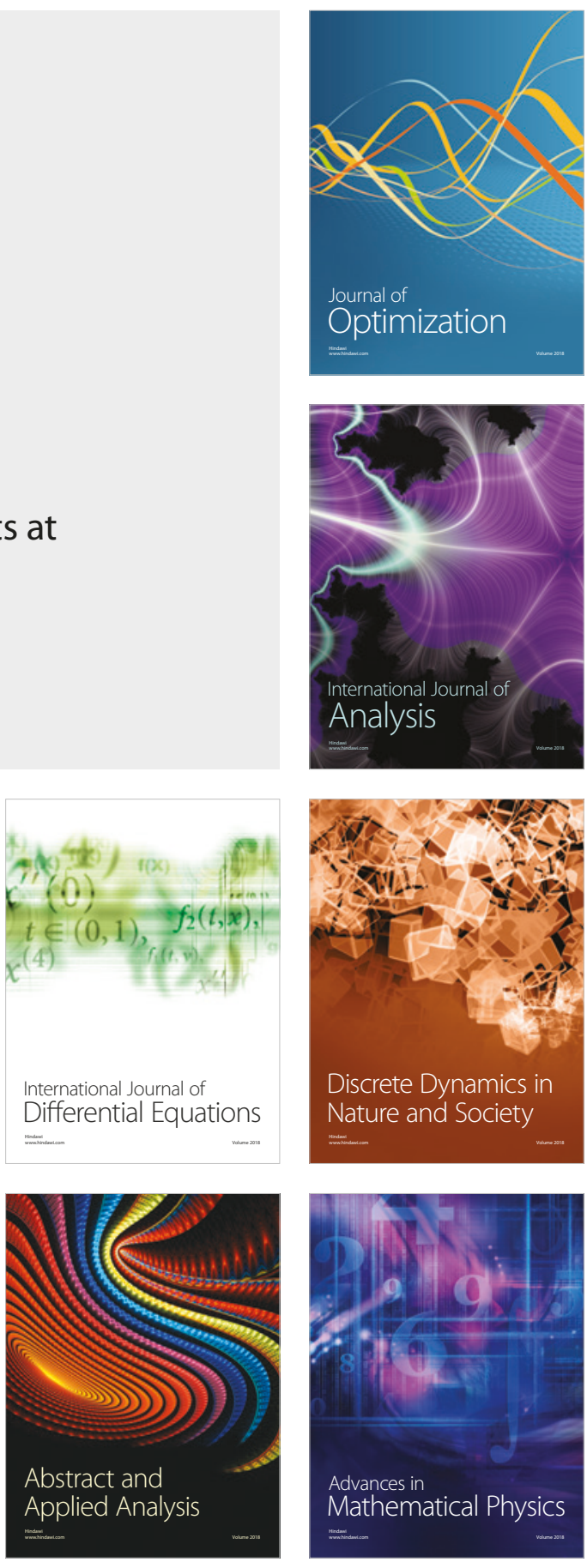